Department for the strength of materials and fatigue testing laboratories; but at the northern end a portion of the basement, some $40 \mathrm{ft}$. deep and $100 \mathrm{ft}$. long, is used as the bottom story of the chemical engineering laboratory, which extends from the basement through to the ground-floor, thus providing access to chemical engineering pilot plants at two levels. On the ground floor the main lecture theatre and teaching laboratories of the Chemical Engineering Department are placed around a central hall in which facilities for student refreshment are provided. The main chemical engineering laboratory is entered from this hall, and on the ground-floor of the laboratory three large sections have been removed from the floor to form the two-story pits through which extraction columns, distillation columns, evaporators, etc., of the Chemical Engineering Department are built. On the northern wall of the laboratory a gallery has been erected $10 \mathrm{ft}$. above ground-level to facilitate the operation of these tall units. The first floor contains the design office of the Chemical Engineering Department, together with research laboratories, conference room, library and office facilities for the chemical engineering staff, and lecture rooms. Similar provisions are made on the upper floors, for the teaching of metallurgy and fuel technology on the second floor, for textile chemistry on the third floor, for industrial biochemistry on the fourth floor, and for machine drawing on the fifth floor.

The building, which is now fully occupied, provides a large lecture room capable of seating 130 students, sound-proofed and fitted with cinema and soundprojection equipment, and fourteen lecture rooms, varying in seating capacity of twenty to sixty, distributed throughout four floors. The chemical engineering drawing office provides adequate working space for sixty students, and the main chemical engineering laboratory provides space for a larger number of students. Further extensive pilot-plant buildings have been erected outside the main chemical engineering building on the area between the building and the River Medlock, a site previously occupied by an old cotton mill built in 1850 . The old mill was pulled down, the area concreted, and on it two large prefabricated steel buildings were erected. In these buildings pilot plants will be built by chemical engineering students as part of their training.

The Metallurgical Department, which is housed on the second floor, contains laboratories for metallurgical analysis, for general metallurgy and for metallography. The main research laboratories of the metallurgy school remain in the extension of the College, since their removal to the new building would have involved very considerable expense, which at this stage was not considered justified. Fuel technology is housed on the second floor, and in addition to the main teaching laboratories includes a number of research laboratories in which the special apparatus required for the investigation of combustion and the analysis of combustion products is housed.

The Textile Chemistry Laboratories on the fourth floor, in addition to providing laboratories for the study of the chemistry of textiles, also provide physical laboratories for the study of the physical properties of textile materials, microscopic analysis and the study of elastomers and plasties, and a number of smaller laboratories in which the research school of the Department will be housed. The Industrial Biochemistry Department on the fourth floor contains, in addition to two large teaching laboratories, several large research laboratories, a media room, an autoclave room, two constant-temperature rooms and one cold room, and each of the laboratories has an inoculation room. The large drawing office on the fifth floor has provision for three hundred students working at one time, although it is divided into rooms by partitions which split the classes into smaller groups.

The project was commenced in May 1956 when the University Grants Committee gave permission for the purchase of the existing cotton mill and for its conversion to a Department of Chemical Engineering. Work on the conversion was commenced in October 1956 and was in part completed by October 1957, when teaching in the first three floors of the building began. The project was completed within fifteen months of the commencement of building operations and has provided a teaching space of 120,000 sq. ft. and additional lecture rooms and seminar rooms of 32,000 sq. ft. at an approximate cost of $£ 488,000$. With this provision the Chemical Engineering Department has expanded from a student intake of twenty-eight students per annum to sixty students in 1957--58, and from 1958-59 it is proposed to accept 120 students per annum. This expansion has been made possible by a corresponding expansion in the teaching staff of the Department, which has grown from a total of six in 1955 to twenty in 1958. The postgraduate research has shown a similar increase, and the visitors to the chemical engineering building were able to see something of the research activities now being carried out in the chemical engineering school. These include studies on mass transfer processes, investigations into the composition of petroleum, studies of corrosion and of the properties of certain protective coatings, the properties of a variety of tower packings and investigations of distillation at reduced pressures.

\title{
THE RADIO RESEARCH STATION, SLOUGH
}

\footnotetext{
$\mathrm{O}^{\mathrm{N}}$ N May 20, members of the Radio Research Board visited the Radio Research Station, one of the establishments of the Department of Scientific and Industrial Research, to inspect the work in progress. On this and the following day, several hundred visitors were invited to see various exhibits and demonstrations at the Station, the new buildings of which were formally opened in June 1957 (see Nature, $180,163 ; 1957)$.
}

The Radio Research Station conducts an extensive programme of research in the fields of radio-wave propagation and allied subjests for which adequate provision is not made elsewhere in Britain. Advice on the nature and extent of this programme is given to the Department by its Radio Research Board, which is an independent body comprising members from industry and the universities, assisted by assessors from the main Government departments 
concerned with the various applications of radio techniques.

A major part of the research programme is designed to assist those responsible for developing and operating radio services in the fields of communications, broadcasting including television, and aids to aerial and marine navigation. The efficient and economical use of the radio-frequency spectrum depends to a major extent on a detailed understanding of the modes of propagation of radio waves at all frequencies and for all conditions of transmission over the ground and through the upper and lower atmosphere. Research is also undertaken on atmospheric noise with the view of minimizing its effect as a source of interference. To assist in the conduct of this work on a world-wide basis, observatories or sub-stations are staffed and maintained at Inverness, Singapore and Port Stanley in the Falkland Islands. Direct co-operative assistance is also provided for similar observatories installed at University College, Ibadan, Nigeria, and at Port Lockroy, Graham Land. Special assistance is being given to the Royal Society's expedition to Halley Bay, Antarctica, for the period of the International Geophysical Year. Radio observations are also being made at Slough and Singapore on transmissions from artifieial Earth satellites.

Apart from this extensive study of radio-wave propagation, research is being conducted on certain characteristics of semi-conductors and on ferrites as materials of special interest in the radio industry. The development of techniques for measuring power, field strength and other quantities at very high radio-frequencies is being pursued, and secondary standards set up where appropriate.

Following extensive work in the past in the detailed study of radio direction-finding over a very wide range of frequencies, more attention has been given recently to the phenomena encountered at very low frequencies $(10-20 \mathrm{kc}$./sec.) in special relation to the use of such long waves for radio aids to navigation. The results displayed to visitors at the Station illustrated the changes in phase and amplitude of the waves observed at various distances up to some $8,000 \mathrm{~km}$. from one or other of the few radio transmitting stations operating on such low frequencies.

More extensive studies of the part played by the ionosphere in the propagation of high-frequency radio waves ( 3 to $30 \mathrm{Mc} / \mathrm{s}$.) to various distances around the world were demonstrated in detail. The ionospheric observatory was engaged in its normal routine of recording the important characteristics of the ionosphere immediately overhead; while various other means were shown of examining the corre. sponding conditions in the ionosphere at points remote from the observer. In a new technique, demonstrated for the first time, a special transmitter has been set up in Malta which sweeps over the frequency band of 5.5-25 Mc./s. in steps of $20 \mathrm{kc}$./s., each step lasting $0.4 \mathrm{sec}$. The receiver at Slough sweeps over the same band, the two sets of equipment being kept in synchronism by very stable crystal clocks. Observations of the signals received under these conditions provide a useful means of studying the ionospheric conditions near the midpoint of the path some $2,000 \mathrm{~km}$, in length. The alternative method of observing the mode of propagation of radio waves over this and greater distances using back-scatter technique was shown in operation; and an interesting cinematograph film entitled "Scatter Sound- ing - a New Technique for Studying High-Frequency Radio Propagation" was also displayed.

The analogous phenomena accompanying the propagation of very short waves by refraction, reflexion and scattering in the troposphere were demonstrated at frequencies ranging from 30 to $10,000 \mathrm{Mc} / \mathrm{s}$. Some interesting results of the radar sounding of the troposphere at vertical incidence were shown, with photographic records illustrating reflexion from discrete layers at heights up to a few kilometres. A new microwave refractometer has been developed for exploring the meteorological conditions in the troposphere and relating these to the associated radio phenomena.

An impressive demonstration was given of the means now used to investigate the nature and source of those atmospheric disturbances which arise from thunderstorms. One set of apparatus was counting lightning flashes occurring within a short radius, $20 \mathrm{~km}$. or so, from the station; while other equipment observed the direction of more distent sources and measured the frequency of occurrence and amplitudes of the resulting atmospherics. This, like much of the other work in progress at the Radio Research Station, is being conducted on a cooperative basis and forms part of the programme of the International Geophysical Year.

Of very topical interest was the actual reception of radio signals from the latest Russian artificial Earth satellite $(1958$ \&) during its orbital passage near Great Britain. As in the case of previous satellites, measurements are being made at Slough of the direction, in elevation and azimuth, of the transmissions and also of the Doppler change in frequency as the satellite approaches and recedes from the Station.

Some of the work demonstrated was concerned with a study of the properties of certain materials, semi-conductors and ferrites, now being used in radio technique. The results of measurements on transistors at low and at high radio frequencies were shown, together with some of the properties at microwave frequencies of ferrites of known composition and structure. In a neighbouring laboratory devoted to measurements of a secondary standard type, a new technique for the accurate measurement of power at centimetre wave-lengths was shown, together with the apparatus for measuring field strength and frequency, and used in connexion with the general work of the Station. At a wave-length in the neighbourhood of $3 \mathrm{~cm}$., powers from $0 \cdot 1$ to $100 \mathrm{~mW}$. can be measured with an error which does not exceed 2-3 per cent.

The scientific work of the Radio Research Station is supported by well-equipped workshops, in which many of the specialized instruments are produced, together with the novel aerial systems used. The library also contained a display of the sources of literature used for the abstracts and references published monthly in the Electronic and Radio Engineer (London) and the Proceedings of the Institute of Radio Engineers (New York). The Station is set in very attractive surroundings. The building, which is functionally designed, is clearly very suitable for its intended purpose; while the surrounding fields of some 200 acres provide adequate space for extensive aerial systems, as well as for the erection of small isolated huts for the conduct of special experiments under conditions free from the interference normally associated with large buildings and populous areas. 